\title{
Lifestyle Behaviors in Black and White Women With a Family History of Breast Cancer
}

\author{
Denise Spectora, Lisa A. DeRoob ${ }^{b}$, and Dale P. Sandlerb \\ Lisa A. DeRoo: DerooL@niehs.nih.gov; Dale P. Sandler: sandler@niehs.nih.gov \\ aGillings School of Global Public Health, University of North Carolina at Chapel Hill, Chapel Hill, \\ NC 27599, USA \\ bEpidemiology Branch, National Institute of Environmental Health Sciences, PO Box 12233, MD \\ A3-05, 111 T.W. Alexander Drive, Research Triangle Park, NC 27709, USA
}

\section{Abstract \\ Objectives-To examine lifestyle behaviors among non-Hispanic Black and White women with a family history of breast cancer and determine the extent to which they meet American Cancer Society (ACS) Nutrition and Physical Activity Recommendations for Breast Cancer Prevention.}

Method-Cross-sectional data from 44,364 women enrolled in the Sister Study (2009), a study of sisters of women with breast cancer within the U.S., were analyzed. Descriptive statistics and chisquare analyses were used to examine body mass index and lifestyle behaviors (e.g., exercise, diet, and smoking) and to determine percentages of women meeting ACS recommendations.

Results-Black women consumed a lower percentage of calories from fat (mean 36.90\% vs. $37.17 \%$ ) and were more likely to meet ACS alcohol recommendations than Whites. White women consumed more fruits and vegetables/day (mean 4.81 vs. 4.41) than Black women and were more likely to meet ACS guidelines for physical activity $(26.4 \%$ vs. $18.2 \%)$ and body mass index (42.5\% vs. $16.7 \%)$.

Conclusion-Despite an elevated risk for breast cancer due to a family history of breast cancer, the majority of women were no more likely than women in the general population to engage in healthy lifestyle behaviors. These women may benefit from lifestyle behavior risk-reduction counseling.

\section{Keywords}

breast cancer risk; lifestyle behaviors; physical activity; overweight/obesity; diet

\footnotetext{
(c) 2011 Elsevier Inc. All rights reserved.

Corresponding author's contact information: Denise Spector, Cancer Health Disparities Post-Doctoral Fellow, Gillings School of Global Public Health Research Associate, Get REAL \& HEEL Breast Cancer Program, CB \#8615, 3433 Country Club Drive, University of North Carolina at Chapel Hill, Chapel Hill, NC 27599, USA, 1-919-962-5755 (Office), 1-919-962-7900 (Fax), dspector@email.unc.edu.

Conflict of interest statement: The authors declare that there are no conflicts of interest.

Publisher's Disclaimer: This is a PDF file of an unedited manuscript that has been accepted for publication. As a service to our customers we are providing this early version of the manuscript. The manuscript will undergo copyediting, typesetting, and review of the resulting proof before it is published in its final citable form. Please note that during the production process errors may be discovered which could affect the content, and all legal disclaimers that apply to the journal pertain.
} 


\section{Introduction}

Modifiable lifestyle factors such as overweight/obesity and adult weight gain (postmenopausal breast cancer), physical inactivity, and alcohol consumption have been linked with breast cancer risk (World Cancer Research Fund, 2007). The relationship between diet and breast cancer is less certain, but a diet high in fat typically leads to increased caloric intake, which can result in overweight/obesity. Family history of breast cancer may enhance the relationship between breast cancer risk and factors such as obesity, physical inactivity, alcohol consumption and smoking (Carpenter et al., 2003; Couch et al., 2001; Sellers, et al., 2002; Vachon et al., 2001; Verloop et al., 2000).

The American Cancer Society (ACS) breast cancer prevention guidelines include the adoption of a physically active lifestyle, maintaining a normal body weight, minimizing lifetime weight gain, and limiting alcohol to no more than one drink/day (Kushi et al., 2006). Differences in lifestyle behaviors between White and Black women have been studied in the general population (Bernstein et al., 2003; Centers for Disease Control (CDC), 2007), but not among women with a breast cancer family history. Aims of this study were to examine whether lifestyle behavior differences exist between Black and White women with a family history of breast cancer and determine the extent to which women adhere to ACS guidelines.

\section{Methods}

Participants

We analyzed baseline data from the Sister Study (www.SisterStudy.org), a prospective study of environmental and genetic risk factors for breast cancer in 50,844 women who have had a sister with breast cancer. Participants are volunteers aged 35 to 74 years from the U.S. and Puerto Rico without breast cancer at time of enrollment. Women completed selfadministered questionnaires and structured telephone interviews on a wide range of known and potential disease risk factors. Participants provided written consent and procedures were approved through the Institutional Review Boards of the National Institutes of Health and Copernicus Group.

Data were from women who completed all baseline enrollment activities as of November 2009. Women were excluded if they: a) were adopted, b) had a prior cancer history, or c) were not White or Black (non-Hispanic), resulting in data from 44,363 non-Hispanic women (40,072 Whites and 4,292 Blacks).

\section{Measures}

We examined demographics and lifestyle-related behaviors. Current physical activity was assessed based on self-reported sports and exercise activities (e.g., walking for exercise, yoga, dance, etc.). Questions included, "In the past 12 months, have you done any sports or exercise activities at least once a week for at least one month?", "How many days per week or per month did you do this?" and "On days that you did this activity, about how much time did you spend on average each day you did this?". Total hours/week of physical activity was calculated from this data.

Current diet (past 12 months) was assessed using a modified-Block food frequency questionnaire (FFQ) (Block et al., 1986). Total daily caloric intake (kcal/day) and percent of total calories from fat were calculated. Fruits and vegetables consumed over the past 12 months were categorized based on daily intake of both combined. Alcohol consumption was classified as never, former, and current, with current drinkers categorized as $\leq 1$ drink/day or greater than 1 drink/day. Body mass index (BMI) (kilograms/meters squared) was calculated 
from height and weight and categorized as: $<18.5$ (underweight), 18.5-24.9 (normal), 25.0-29.9 (overweight), and $\geq 30.0$ (obese) (CDC, 2008).

\section{Analysis}

Descriptive statistics were generated using frequencies and percentages and chi-square statistics to compare White and Black women on demographic factors, smoking, and body mass index. Similar analyses were conducted to determine the percentage of women meeting the ACS breast cancer prevention recommendations. We calculated means as the measure of central tendency and $25^{\text {th }}, 50^{\text {th }}$, and $75^{\text {th }}$ percentiles as measures of variability for physical activity and dietary behaviors.

\section{Results}

The mean ages for non-Hispanic White and Black women were 55.4 and 53.1 years, respectively. Most women $(85 \%)$ had at least a college degree. Black women were more likely than White women to have a household income $<\$ 50,000$ and to have never married or be divorced. Overweight and obesity were more prevalent in Black women than White women ( $83.0 \%$ vs. $57.5 \%)$. Black women exercised less (mean 2.31 vs. 2.89 hours a week) and consumed less fruits \& vegetables/day (4.41 vs. 4.81) (Table 1), whereas White women were more likely to consume a higher $\%$ of their total daily kcal from fat.

Most women did not meet the ACS recommendation for physical activity or BMI, although White women were more likely to have a BMI $<25(42.5 \%$ vs. $16.7 \%)$ and were more likely to exercise $\geq 4$ hours/week ( $26.4 \%$ vs. $18.2 \%$ ) (Table 2). Most women met the ACS recommendation of $\leq 1$ alcoholic drink/day with a higher percentage of Black women meeting the recommendation than White women. Only $12.7 \%$ of White and $4.5 \%$ of Black women met all three recommendations.

\section{Discussion}

Women in our study appeared no more likely to have a normal BMI or engage in healthy lifestyle behaviors than women in the general population despite their greater risk for breast cancer due to family history (Bernstein et al., 2003; CDC, 2007). In a national sample, the majority of both White and Black women were overweight or obese, although Black women had a substantially higher prevalence of obesity than White women (45\% versus $24 \%$ ) (National Center for Health Statistics, 2007). In general, overweight/obesity is related to post-menopausal breast cancer, but it is unclear whether it is related to breast cancer risk in Black women. The few studies among Black women have yielded conflicting results. Hall et al. (2000) found no association between an elevated BMI and pre- or post-menopausal breast cancer in Black women, but found a high waist-to-hip ratio increased breast cancer risk in both pre-menopausal Black and White women.

Our finding that Black women were less likely to engage in regular physical activity compared to White women is similar to other reports (Bernstein et al., 2005; CDC, 2007). An inverse association between physical activity and breast cancer risk has been reported (Patel \& Bernstein, 2006; World Cancer Research Fund, 2007), including studies in Black women (Adams-Campbell et al., 2001; Bernstein et al., 2005). Previous studies have reported lower fruit and vegetable intake and less alcohol consumption among Black women compared to White women, but no significant differences in dietary fat intake (Forshee et al., 2003). 


\section{Limitations}

Compared to women in the general population, participants have higher education and income levels. However, other demographic and breast cancer risk factors (e.g., age at menarche, reproductive history, lactation history, etc.) are similar to women in the general population. This was a cross-sectional study so it is not possible to determine if lifestyle behaviors changed after the sister's breast cancer diagnosis. We lacked information on perceived risk or control, which may influence lifestyle behaviors. Participants may not be representative of women with a family history of breast cancer because they were volunteers. Although questionnaires are widely used to collect information on diet and physical activity, such data are subject to misclassification and bias (Ferrari, 2007; Herbert et al., 2002). Black women were heavier despite reporting a lower proportion of calories from fat; the FFQ may not have fully captured Blacks' diets or there may have been differences in quality of reporting.

\section{Conclusions}

To our knowledge this is the first study to examine lifestyle behavioral differences among non-Hispanic Black and White women with a family history of breast cancer. Despite their family history, the majority of women did not meet ACS guidelines for weight and exercise. This was especially true for Black women. Given the evidence suggesting that obesity and physical inactivity may further increase breast cancer risk among women with a family history, our findings suggest that these women may benefit from education aimed at motivating them to engage in healthier behaviors.

\section{Acknowledgments}

The first author would like to acknowledge the American Cancer Society for their support through a Doctoral Degree Scholarship in Cancer Nursing (grant number DSCN-07-132-01). This work was also funded, in part, by the Intramural Research Program of the NIH, National Institute of Environmental Health Sciences (Z01 ES0044005). A special thanks to the supportive staff of the Sister Study, especially Dan Scharf for programming assistance.

\section{References}

Adams-Campbell LL, Rosenberg L, Rao RS, Palmer JR. Strenuous physical activity and breast cancer risk in African-American women. J Natl Med Assoc. 2001; 93:267-275. [PubMed: 11491277]

Bernstein L, Patel AV, Ursin G, et al. Lifetime recreational exercise activity and breast cancer risk among black women and white women. J Natl Cancer Inst. 2005; 97:1671-1679. [PubMed: 16288120]

Bernstein L, Teal CR, Joslyn S, Wilson J. Ethnicity-related variation in breast cancer risk factors. Cancer. 2003; 97(suppl. 1):222-229. [PubMed: 12491485]

Block G, Hartman AM, Dresser CM, Carroll MD, Gannon J, Gardner L. A data-based approach to diet questionnaire design and testing. Am J Epidemiol. 1986; 12:453-69. [PubMed: 3740045]

Carpenter CL, Ross RK, Paganini A, Bernstein L. Effect of family history, obesity and exercise on breast cancer risk among postmenopausal women. Int J Cancer. 2003; 106:96-102. [PubMed: 12794763]

Centers for Disease Control and Prevention (CDC). Behavioral Risk Factor Surveillance System Survey Data. Atlanta, GA: U.S. Department of Health and Human Services, Centers for Disease Control and Prevention; 2007.

Centers for Disease Control and Prevention (CDC). Healthy Weight: It's not a Diet, It's a Lifestyle. 2008. Retrieved October 26, 2008, from http://www.cdc.gov/nccdphp/dnpa/healthweight/assessing/bmi/adult_BMI.htm

Couch FJ, Cerhan JR, Vierkant RA, et al. Cigarette smoking increases risk for breast cancer in highrisk breast cancer families. Cancer Epidemiol Biomarkers Prev. 2001; 10:327-332. [PubMed: 11319172] 
Ferrari P, Friedenreich C, Matthews CE. The role of measurement error in estimating levels of physical activity. Am J Epidemiol. 2007; 166:832-840. [PubMed: 17670910]

Forshee RA, Storey ML, Ritenbaugh C. Breast cancer risk and lifestyle differences among premenopausal and postmenopausal African-American women and White women. Cancer. 2003; 97(suppl. 1):280-288. [PubMed: 12491492]

Hall IJ, Newman B, Millikan RC, Moorman PG. Body size and breast cancer risk in black women and white women: The Carolina Breast Cancer Study. J Epidemiol. 2000; 151:754-764.

Herbert JR, Ebbeling CB, Matthew CE, et al. Systematic error in middle-aged women's estimates of energy intake: Comparing three self-report measures to total energy expenditures from doubly labeled water. Ann Epidemiol. 2002; 12:577-586. [PubMed: 12495831]

Kushi, LH.; Byers, T.; Doyle, C., et al. CA Cancer J Clin. Vol. 56. 2006. American Cancer Society guidelines on nutrition and physical activity for cancer prevention: Reducing risk of cancer with healthy food choices and physical activity; p. 254-281.

National Center for Health Statistics. Hyattsville, MD: 2007. Health, United States, 2007, with Chartbook on Trends in the Health of Americans. Retrieved November 12, 2008, from http://www.cdc.gov/nchs/data/hus/hus07.pdf

Patel, AV.; Bernstein, L. Physical activity and cancer incidence: Breast cancer. In: McTiernan, A., editor. Cancer prevention and management through exercise and weight control. Taylor \& Francis; New York: 2006. p. 49-74.

Sellers TA, Davis J, Cerhan JR, et al. Interaction of waist/hip ratio and family history on the risk of hormone receptor-defined breast cancer in a prospective study of postmenopausal women. Am J Epidemiol. 2002; 155:225-233. [PubMed: 11821247]

Vachon CM, Cerhan JR, Vierkant RA, Sellers TA. Investigation of an interaction of alcohol intake and family history on breast cancer risk in the Minnesota Breast Cancer Family Study. Cancer. 2001; 92:240-248. [PubMed: 11466675]

Verloop J, Rookus MA, van der Kooy K, van Leeuwen FE. Physical activity and breast cancer risk in women aged 20-54 years. J Natl Cancer Inst. 2000; 92:128-135. [PubMed: 10639514]

World Cancer Research Fund. Food, nutrition, physical activity, and the prevention of cancer: A global perspective. America Institute for Cancer Research; Washington, DC: 2007. 


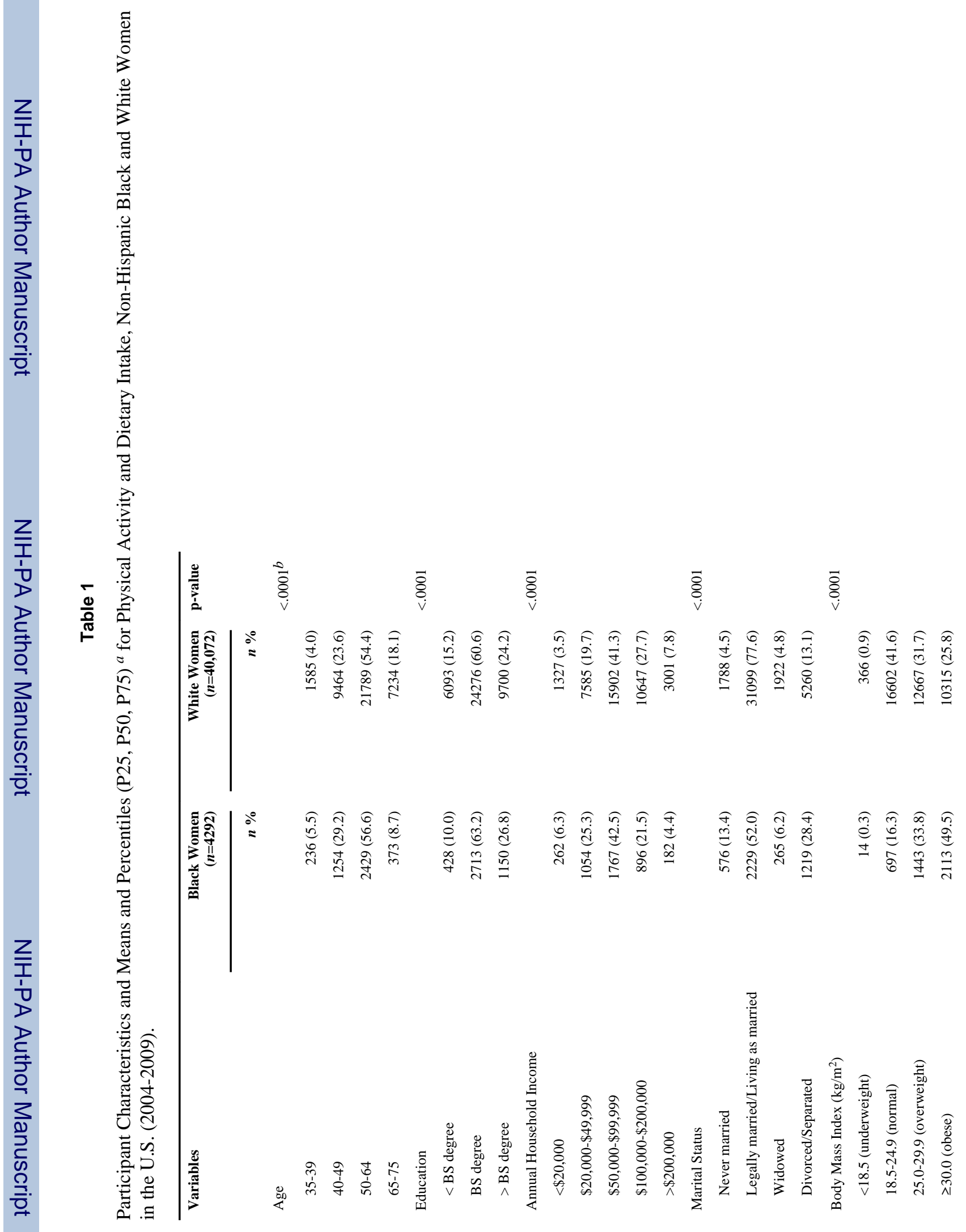


Spector et al.

Page 7

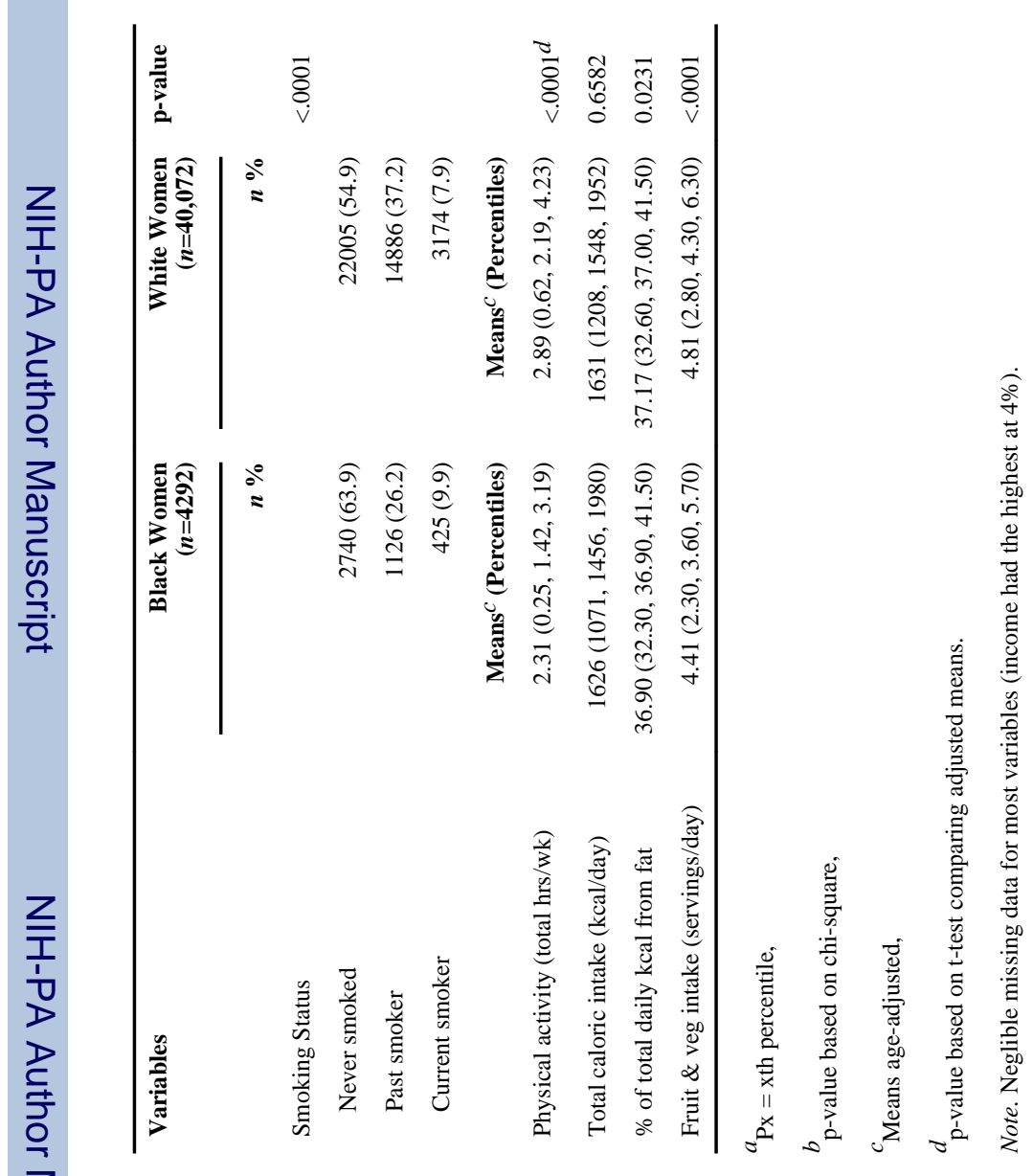

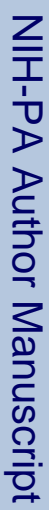

Prev Med. Author manuscript; available in PMC 2012 May 1. 


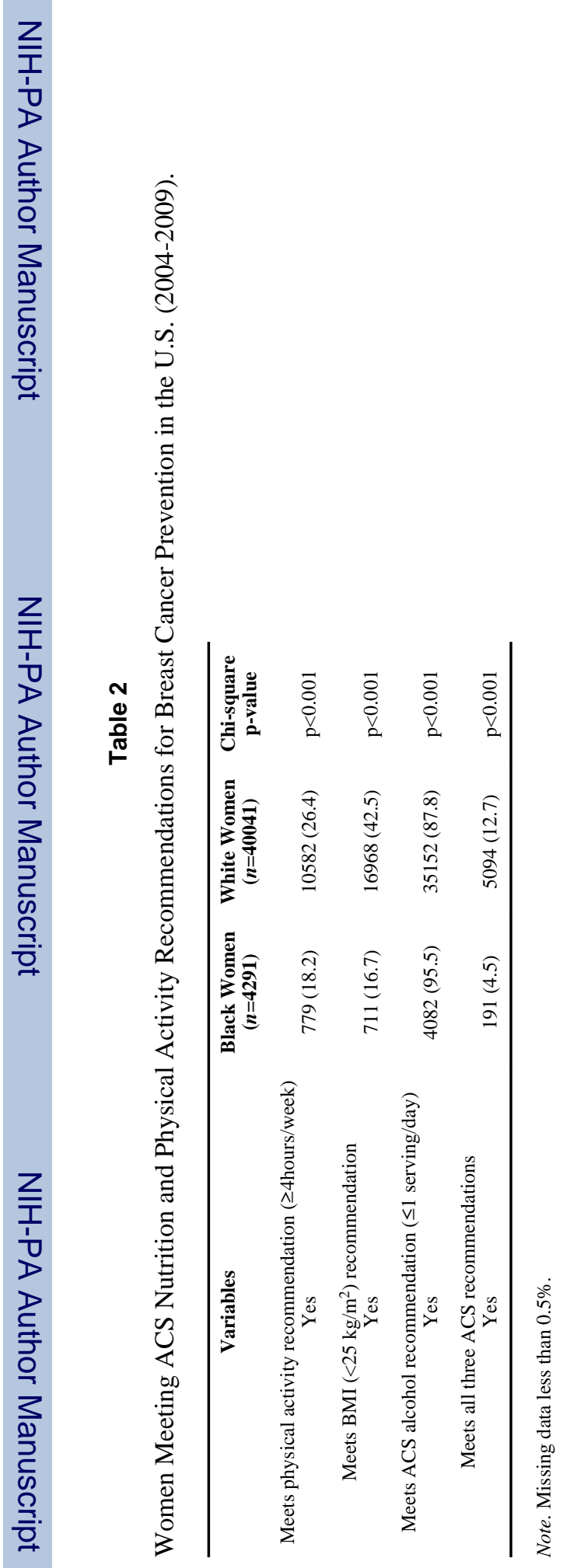

